\title{
Inclusão digital: Um estudo preliminar sobre conceitos, dimensões, e implicações na sociedade
}

\author{
Airton Zancanaro ${ }^{1}$, Carla Grossl ${ }^{1}$, Deborah Kosak Klagenberg ${ }^{1}$, Kemely Kedny \\ Pezzini $^{1}$, Letícia Hümmelgen ${ }^{1}$, Nágila Cristina Hinckel ${ }^{1}$, Thainá Schroeder Ribeiro ${ }^{1}$ \\ ${ }^{1}$ Instituto Federal Catarinense - Campus São Bento do Sul - Rua Paulo Chapiewski, ${ }^{\circ}$ \\ 931, Bairro Centenário - 89283-064 - São Bento do Sul - SC - Brazil \\ airton.zancanarodifc.edu.br, \{carlagrossl05, klagenberg.deborah, \\ kemypezzini, letihummelgen\}@gmail.com, nagila.hinckel@ifc.edu.br, \\ ribeirothay28@gmail.com
}

\begin{abstract}
Digital technologies are increasingly present in society, however, they aren't all thought to include people, in that way, promoting exclusion. The article shows the problem: What are the dimensions of digital inclusion in society and what are the impacts of this insertion in the lives of the subjects? The objective seeks to understand the dimensions of digital inclusion and the impacts it has on society, through research of a basic nature, descriptive approach and proceedings of a bibliographic analysis. The results expect to materialize the dimensions human, social, physical and technological of digital inclusion which is supported by didactic and communication, it will serve as a base to construct a digital inclusion method.
\end{abstract}

Resumo. As tecnologias digitais estão cada vez mais presentes na sociedade, no entanto, nem sempre elas são pensadas de forma a incluir, promovendo assim a exclusão. Este artigo tem a problemática: Quais as dimensões da inclusão digital na sociedade atual e quais os impactos da sua inserção na vida dos sujeitos? Como objetivo busca-se compreender as dimensões da inclusão digital e seus impactos na sociedade, por meio de uma pesquisa de natureza básica, abordagem descritiva e procedimentos de análise bibliográficos. Espera-se materializar as dimensões humana, social, física e tecnológica da inclusão digital, que amparadas pela didática e comunicação, servirão de base para construção de um método de inclusão digital.

\section{Tecnologia, sujeito e sociedade}

A tecnologia, especialmente a digital, vem se tornando o centro das relações e das práticas em sociedade. A pandemia e o distanciamento social, tornaram ainda mais emergente a necessidade de acesso e de conhecimento para utilização de ferramentas tecnológicas digitais (MALAVÉ, 2020).

Ao mesmo tempo que esse movimento possibilitou uma "nova forma" de viver/conviver em sociedade, acabou por potencializar o abismo da exclusão digital. Nesse sentido, a inclusão digital é um caminho importante para superar a exclusão e o analfabetismo relacionado ao desconhecimento do uso de tecnologias digitais. Analisando esse contexto, tem-se como problemática central deste trabalho compreender quais são as dimensões da inclusão digital na sociedade atual e quais os impactos da sua inserção na vida dos sujeitos.

Os sujeitos, presentes nessa problemática possuem uma relação íntima com a 
sociedade. De acordo com Elias (1994), existe um processo de correlação cíclica entre sociedade e os indivíduos, pois ao mesmo tempo em que os indivíduos compõe a sociedade e a modificam, a sociedade e a tecnologia também mudam a forma dos indivíduos serem e se relacionarem entre si e com a sociedade. Castells (2005, p.43) corrobora dizendo que a "[...] tecnologia é a sociedade, e a sociedade não pode ser entendida ou representada sem suas ferramentas tecnológicas". Cria-se então uma relação preestabelecida entre os sujeitos e a sociedade em constante movimento.

\section{Conceitos norteadores na perspectiva da inclusão digital}

Como base para atingir o objetivo proposto por este artigo, buscou-se compreender os conceitos e elementos que sustentam as possíveis dimensões da inclusão digital. Evidente, que ao falar que há necessidade de incluir digitalmente, indiretamente apontase à existência da exclusão. Vale enfatizar que todo esse cenário só se constitui, pela presença da tecnologia na sociedade e pelo papel que essa tecnologia representa na vida das pessoas em sociedade. Para tal, algumas terminologias necessitam ser abordadas, para que seja possível identificar as dimensões que compreendem a inclusão digital (Quadro 1).

Quadro 1. Conceitos, autores e definições/contribuições

\begin{tabular}{|l|l|l|}
\hline Conceito & Autor & Definição/Contribuição do conceito \\
\hline $\begin{array}{l}\text { Inclusão } \\
\text { Digital }\end{array}$ & $\begin{array}{l}\text { De Luca (2004, p. } \\
\text { 09 apud Melo, } \\
\text { 2006, p. 06) }\end{array}$ & $\begin{array}{l}\text { "[..] a inclusão digital deve favorecer a apropriação da } \\
\text { tecnologia de forma consciente, que torne o indivíduo capaz } \\
\text { de decidir quando, como e para que utilizá-la". }\end{array}$ \\
\hline $\begin{array}{l}\text { Exclusão } \\
\text { Digital }\end{array}$ & $\begin{array}{l}\text { Almeida e Paula } \\
\text { (2005, p. 57) }\end{array}$ & $\begin{array}{l}\text { "É um estado no qual um indivíduo é privado da utilização } \\
\text { das tecnologias de informação e comunicação, seja pela } \\
\text { insuficiência de meios de acesso, seja pela carência de } \\
\text { conhecimento ou por falta de interesse." }\end{array}$ \\
\hline $\begin{array}{l}\text { Acessibilida } \\
\text { de }\end{array}$ & $\begin{array}{l}\text { Torres, Mazzoni } \\
\text { e Alves (2002) }\end{array}$ & $\begin{array}{l}\text { Utilização de recursos digitais em qualquer lugar e/ou } \\
\text { momento por qualquer pessoa sem distinção, } \\
\text { independentemente de limitação, situação ou tecnologia. }\end{array}$ \\
\hline $\begin{array}{l}\text { Letramento } \\
\text { Digital }\end{array}$ & $\begin{array}{l}\text { Soares (2002, } \\
\text { p.151) }\end{array}$ & $\begin{array}{l}\text { "Um certo estado ou condição que adquirem os que se } \\
\text { apropriam da nova tecnologia digital e exercem práticas de } \\
\text { leitura e de escrita na tela, diferente do estado ou condição - } \\
\text { do letramento - dos que exercem práticas de leitura e de } \\
\text { escrita no papel." }\end{array}$ \\
\hline $\begin{array}{l}\text { Analfabetis } \\
\text { mo Digital }\end{array}$ & Duran, 2008 & $\begin{array}{l}\text { Corresponde ao não domínio de operações básicas que } \\
\text { envolvem o uso da linguagem digital a partir da qual operam } \\
\text { as TICs. }\end{array}$ \\
\hline $\begin{array}{l}\text { Métodos de } \\
\text { Ensino }\end{array}$ & $\begin{array}{l}\text { Bonilla e Pretto } \\
\text { (2011) }\end{array}$ & $\begin{array}{l}\text { Representa a maneira como o professor organiza suas } \\
\text { propostas educativas para atingir os seus objetivos de } \\
\text { ensino/aprendizagem. A escolha do método é fundamental } \\
\text { para aproximar o processo de aprendizagem ao processo de } \\
\text { inclusão digital. }\end{array}$ \\
\hline
\end{tabular}

Com base nesses conceitos e nos estudos realizados nas obras supracitadas, compreendeu-se as possíveis ${ }^{1}$ dimensões da inclusão digital: social, humana, tecnológica e física, e que trabalhadas em conjunto tem potencial de proporcionar ao indivíduo a possibilidade de inclusão. Quando uma dessas dimensões falha, as outras

1 Diz-se possíveis, pois a ideia de conjunção destas dimensões para a inclusão digital, parte de uma hipótese levantada pelo grupo de pesquisa, para ser o plano de fundo na construção de uma metodologia, para o desenvolvimento de processos de inclusão no mundo digital. 
dimensões ficam à mercê de falhas também, o que pode acarretar a exclusão digital. A falta de acessibilidade e de letramento levam ao analfabetismo digital, que pode ser considerado um fator de exclusão (BONILLA E PRETTO,2011). Pode-se então perceber que os conceitos estão relacionados entre si, na perspectiva da inclusão digital.

\section{A materialização das dimensões da inclusão digital}

Como resultado da pesquisa bibliográfica realizada, foram compreendidas quais são as dimensões para o processo de inclusão digital. Estas, por sua vez, são representadas por eixos que se interconectam e são sustentados por processos de comunicação e movimentados pela didática.

Buscando materializar este entendimento, construiu-se uma representação que pudesse demonstrar o potencial de conexão entre as dimensões e seu impacto sobre os processos de inclusão e exclusão digital dos indivíduos, frente às tecnologias de informação e de comunicação, na sociedade. Na Figura 01, cada um dos eixos configura-se em uma dimensão. A dimensão tecnológica é representada pelo acesso à tecnologia, ou seja, aos equipamentos e ferramentas digitais presentes na sociedade. A dimensão social envolve o contexto socioeconômico e cultural dos sujeitos, que são objetos da inclusão e aponta para a relação do indivíduo com a comunidade, com o mundo do trabalho, suas relações e como estes influenciam em seus interesses. A dimensão humana é representada pelos profissionais que atuarão no desenvolvimento das práticas de inclusão digital e a dimensão física, por sua vez, corresponde ao ambiente onde o processo de ensino e aprendizagem será desenvolvido.

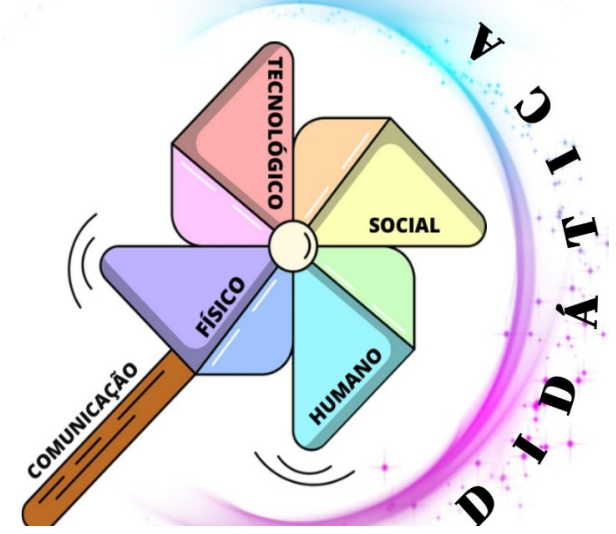

Figura 01. Dimensões da inclusão digital

Para que seja possível aproximar-se de um processo de inclusão digital, as dimensões não podem ser percebidas de forma isolada, ou seja, devem ser pensadas em conjunto, visto que todos são pilares importantes para a fundamentação dessa perspectiva. Vale ressaltar, que mesmo conectando os eixos do catavento existem dois aspectos que são importantes para a efetividade de um método pautado nestas dimensões. O primeiro deles é a comunicação, que representa a haste de sustentação entre cada um dos eixos, ou seja, a comunicação é a base para que cada uma das dimensões se conectem e "conversem", entendendo sua parte como fragmento do todo no processo de inclusão digital. De acordo com Pinheiro (2005) a comunicação envolve a construção de significados entre o sujeito que emite a mensagem e aquele que a interpreta, tendo como critério adicional a intencionalidade, que segundo Santaella 
(2001) é uma atividade direcionada a um objetivo e que pode ser validada. Esta intencionalidade, junto ao processo de comunicação, constitui-se como o segundo aspecto, que representa a força motriz para o movimento destas dimensões, na busca por métodos inclusivos, identificada, na Figura 01, pela didática.

Para que a comunicação aconteça é preciso que os sujeitos se compreendam. Já, para que a aprendizagem ocorra, faz-se necessário ensinar de uma forma que o outro seja capaz de aprender. Nesse sentido, a didática, somada a todos os outros elementos do catavento, fecha o ciclo da inclusão digital, provendo os estímulos cognitivos necessários para o desenvolvimento e aprendizagem dos sujeitos.

O resultado destes estudos subsidiará o desenvolvimento de um método de inclusão digital a ser desenvolvido pelos autores. Por fim, entende-se que a criação de metodologias que visam incluir digitalmente devem considerar estas dimensões, para que os processos de ensino em vez de incluir, não se tornem fatores de potencialização da exclusão digital e, consequentemente, social.

\section{Considerações Finais}

Neste estudo buscou-se compreender os conceitos de inclusão e exclusão digital, seus desafios e manifestações bem como suas dimensões acerca da sociedade contemporânea. Essas dimensões humana, social, tecnológica e física, sustentadas pela comunicação e movidas pela didática, foram sintetizadas na figura de um catavento e são o resultado do estudo das obras pesquisadas. Com isso foi possível compreender os seus impactos na sociedade.

\section{Referências Bibliográficas}

ALMEIDA, Lília Bilati; PAULA, Luiza Gonçalves. de; CARELLI, Flávio Campos; OSÓRIO, Tito Lívio Gomes; GENESTRA, Marcelo. O retrato da exclusão digital na sociedade brasileira. Revista de Gestão da Tecnologia e Sistemas de Informação. Volta Redonda, v. 2, n. 1, p. 55-67, 2005.

BONILLA, Maria Helena Silveira, e PRETTO, Nelson De Luca, orgs. Inclusão digital: polêmica contemporânea. Salvador: EDUFBA, 2011.

CASTELLS, Manuel. A sociedade em rede. Rio de Janeiro: Paz e Terra, 2005.

ELIAS, Norbert. A sociedade dos indivíduos. Rio de Janeiro: Ed. Zahar, 1994.

MALAVE, Mayra. O papel das redes sociais durante a pandemia. Instituto Fiocruz IFF, 2020. Acesso em: outubro/2020. Disponível em: http://www.iff.fiocruz.br/index.php/8-noticias/675-papel-redes-sociais

MELO, Janete Aparecida Pereira. Saberes e conceitos sobre a inclusão digital. São Paulo: Abed, 2006. 11 p.

PINHEIRO, Daíse Cristina de Sá. O papel do plano de comunicação preventivo em momento de crise na organização. 2005. 58 f. TCC (Doutorado) - Curso de Comunicação Social, Habilitação em Jornalismo, Faculdade de Comunicação e Biblioteconomia, Universidade Federal de Goiás, Goiania, 2005.

SANTAELLA, Lucia. Comunicação e pesquisa: projetos para mestrado e doutorado. 1.ed. São Paulo: Hacker Editores, 2001.

SOARES, Magda. Novas práticas de leitura e escrita: letramento na cibercultura. Educação e Sociedade, Campinas: CEDES, v. 23, n. 81, p. 143-160, 2002. 